\title{
EPICTETO Y FOCÍLIDES DE QUEVEDO: \\ UN MANUSCRITO DE FINES DEL SIGLO XVIII
}

Los manuscritos copiados de ediciones impresas suelen contarse entre los más curiosos y enigmáticos. Unas veces se explican por razones económicas, cuando se puede ver que el tiempo gastado en la copia $y$ los materiales en ella utilizados deben haber sido menos caros que el precio del libro impreso. Otras veces, por el contrario, denotan una bibliofilia de ostentación, cuando es visible que en ellos se hicieron largos gastos de tiempo y de materiales. El manuscrito que describiremos a continuación no cabe exactamente en ninguna de las dos categorias. La forma en que se publica una obra puede no corresponder a las preferencias o a las necesidades del coleccionista o estudioso, haciendo, si no necesaria, a lo menos preferible una versión distinta de la impresa, o sea, antes de la invención de la máquina de escribir, una copia manuscrita. El manuscrito que nos ocupa (perteneciente a una colección particular) parece corresponder a ciertas preferencias o necesidades especiales del coleccionista. No parece haberse conocido ni descrito antes.

A. / Sistemas filosoficos / de / Epícteto, y Focílides.

$19.5 \times 14.5 \mathrm{cms}$. 73 hojas, verde claro, con dos de guardas: hoja en blanco, portada, dos hojas s. num., fols. 1-51 y 1-15 [bis], numerados en el margen extremo superior de la derecha con escritura idéntica a la del texto (falta aquí y allá un número, cortado al encuadernarse el manuscrito), tres hojas en blanco. Las hojas están ligeramente marcadas a lápiz para limitar márgenes y texto $(15.5 \times 10$ cms.). Texto en tinta negra. Escritura cursiva del siglo xvir.

Filigrana: MALLO

$\mathbf{S}$

Un cuaderno de 4 hojas y 7 de 10 , incluyendo la hoja final de guardas. Los cuadernos de 10 llevan signaturas, de 1 a 7 , en el margen superior izquierdo de los fols. 1, 11, 21, 31, 41, 51 y 10 [bis]. La filigrana aparece 23 veces en el pliego de hojas cónyuges, o cerca de él, al centro, dividido normalmente de manera que "Mallo" aparece en una hoja y la $S$ invertida en la otra. Las hojas que no llevan filigrana parecen ser un poco más oscuras. Es posible que se haya utilizado un papel corriente de escritorio (de unos $31 \times$ 22 cms.), doblado y luego cortado para la encuadernación.

Encuadernación (contemporánea del ms.): gamuza, color café con leche, sobre cartones, de $20 \times 14.8 \mathrm{cms}$.; 4 nervios; 4 cintas de seda azul (rotas); listón de marcar en seda azul gris; cortes pintados de rojo.

Procedencia: Bardón López (Calálogo 60, Madrid, 1970, núm. 893). Contenido:

1. Extracto de la vida del Traductor de Epicte (c) to y Focilides (fols. [a]-[b]) . 
2. Doctrina de Epicte (c) to. / Traducida por / Don Francisco de Quevedo Villegas. "Las cosas exterior, è interiormente..... pues no está el acallarlos en tu mano": 60 capítulos, silvas (fols. 1-5lr).

3. Noticias de Epícteto (fol. 51r-v).

4. EL FOCILIDES. / Traducido por el mismo Autor. Amonestacion: 4 endecasílabos. "No te engañe la industria y diligencia.... muerte dichosa, y gloria despues de ella": endecasílabos sueltos (fols. $1-15 \mathrm{v}$ ).

Con muy pocas y ligeras variantes ortográficas, los textos de Epicteto y de Focílides se han copiado del Parnaso español de Sedano, editado por Antonio de Sancha, donde aparecen en el tercer tomo (Madrid, 1770, reproducido en 1782), pp. 118-210. Hasta el error en el título, "Epitecto", cometido en el Parnaso (p. 118), aparece en el ms. (portada y fols. [a] y 1), si bien corregido luego por la misma mano. E1 "Extracto" de la vida de Quevedo no es, por otra parte, sino una versión abreviada de la noticia que aparece en las pp. xxv-xlvi del cuarto tomo del mismo Parnaso (1770, reimpreso en 1776). En cuanto a la fuente de las "Noticias de Epícteto", va identificada al fin del mismo texto, con algunos errores ortográficos: "Les vies de plùs illustres philosophes de l'antiquité, trad. del Griego de Diogenes Laercio", que es la traducción de este autor por J. G. de Chauffepié, ...A Auxquelles on a ajouté la vie de l'auteur, celles d'Epictète..., etc., Amsterdam, 1758, 3 vols. ("La Vie d'Epictéte", extractada en nuestro manuscrito, está en el t. 3, pp. 28-56).

Antes del Parnaso, las traducciones de Epicteto y Focílides habían aparecido en la edición de obras de Quevedo publicada en Madrid en 1729. Casi inmediatamente después de la primera edición del Parnaso (1770), se volvieron a publicar en el segundo tomo de las obras de Quevedo impresas por Ibarra (Madrid, 1772), y luego en la edición de sus Obras por Sancha (1790-1794). Esta edición incluye también los varios ensayos de Quevedo sobre sus traducciones, con las vidas de Epicteto y de Focílides (tomo 5, 1790), así como la extensa biografía de Quevedo por Pablo Antonio de Tarsia (tomo 10, 1791), todo lo cual le importaba evidentemente al dueño del manuscrito, de manera que podemos pensar que le hubiera interesado adquirir la edición de Sancha. Ésta nos daría, así, un terminus ante quem para la elaboración del manuscrito. Nuestra hipótesis es que éste se hizo poco después de 1770 y casi seguramente antes de 1790. Las demás obras de Quevedo que figuran en los distintos tomos del Parnaso (varios poemas originales de diversos metros) no se incluyen en el manuscrito. La letra "A" que encabeza el título de la portada sugiere el plan de una serie de manuscritos, y deja abierta la posibilidad de que existan otros, que pueden contener más obras de Quevedo, o traducciones, u obras filosóficas.

THEOdore S. BEARdSLEy, JR.

The Hispanic Society of America. 